\title{
THE EPIDEMIOLOGY OF DEVELOPMENTAL DYSPLASIA OF THE HIP IN MALES
}

\section{EPIDEMIOLOGIA DA DISPLASIA DO DESENVOLVIMENTO DO QUADRIL NO SEXO MASCULINO}

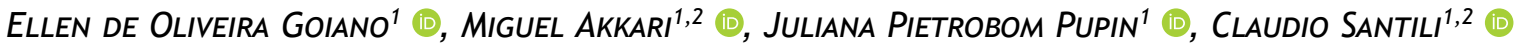 \\ 1. Santa Casa de São Paulo, Pediatric Orthopedics and Traumatology Group, São Paulo, SP, Brazil. \\ 2. Santa Casa de São Paulo, Faculdade de Ciências Médicas, São Paulo, SP, Brazil.
}

\section{ABSTRACT}

Developmental Dysplasia of the Hip (DDH) is one of the most common orthopedic hip diseases of the pediatric population. There is a predominance in females and patients with known risk factors. Objective: To evaluate the characteristics of DDH in a reference center and compare them with the literature. Methods: This is a cross-sectional observational study based on the review of medical records and radiographs from which epidemiological data such as laterality, age at diagnosis, acetabular index, radiographic classification and others were collected. Results: A total of 297 medical records were found between May 1974 and June 2009. Of those, 147 patients (216 affected hips) were eligible for the survey. Most of the patients came from the state of São Paulo (91.1\%), were born in autumn/winter (66.7\%), reported as Caucasians (76.9\%), with bilateral involvement (46.9\%) and mean age at diagnosis of 22.8 months. Conclusion: The most frequent type of DDH was high dislocation (28.7\%), and the acetabular index progressively increased with the age. The International Hip Dysplasia Institute classification was found to be more reproducible than Tönnis classification. Delayed diagnosis was associated with the absence of risk factors and with bilaterality. Level of Evidence III, Retrospective comparative study.

Keywords: Hip Dislocation. Hip Dislocation, Congenital. Epidemiology.

\section{RESUMO}

A displasia do desenvolvimento do quadril (DDQ) é uma das alterações ortopédicas mais frequentes na população pediátrica. Há predominância no sexo feminino e em pacientes com fatores de risco conhecidos. Objetivo: Avaliar as características da DDQ no sexo masculino de um grande centro de referência e cotejá-las com a literatura. Métodos: Trata-se de estudo observacional transversal baseado na revisão de prontuários e radiografias de onde foram coletados dados epidemiológicos tais como lateralidade, idade no diagnóstico, índice acetabular, classificação radiográfica e outros. Resultados: Foram encontrados 297 prontuários no período de maio de 1974 a junho de 2009. Destes, 147 pacientes (216 quadris afetados) foram elegíveis para a pesquisa. A maioria dos pacientes era procedente do estado de São Paulo (91,1\%), nascidos no outono/inverno (66,7\%), autodeclarados caucasianos (76,9\%), com acometimento bilateral (46,9\%) e idade média no diagnóstico de 22,8 meses. Conclusão: O tipo de DDQ mais encontrado foi a luxação alta (28,7\%); o índice acetabular apresentou-se progressivamente aumentado quanto maior a idade do paciente. A classificação do International Hip Dysplasia Institute mostrou-se mais reprodutivel que a Classificação de Tönnis. O atraso no diagnóstico foi associado à ausência de fatores de risco e à bilateralidade. Nível de Evidência III, Estudo retrospectivo comparativo.

Descritores: Luxação do Quadril. Luxação Congênita de Quadril. Epidemiologia.

Citation: Goiano EO, Akkari M, Pupin JP, Santili C. The epidemiology of developmental dysplasia of the hip in males. Acta Ortop Bras. [online]. 2020;28(1):26-30. Available from URL: http://www.scielo.br/aob.

\section{INTRODUCTION}

Developmental Dysplasia of the Hip (DDH) is a multifaceted condition of the pediatric hip that can present clinically in different ways. Cases of transient neonatal hip instability, as well as isolated acetabular dysplasia, to severe cases of open dislocation where there is a primitive acetabulum and/or acetabular neoformation are treated in the orthopedic routine. In recent decades there has been considerable evolution in the diagnosis and treatment protocols of DDH and many epidemiological aspects as well as risk factors have been studied. ${ }^{1-4}$ It is known, for example, that there is a prevalence of unilateral disease and the most affected side is the left side, the white race and the female sex are more frequently associated with the condition, and the risk factors include pelvic presentation, oligohydramnios, among others. ${ }^{4-5}$ However, little is known about the characteristics of DDH in males and if there are sex differences in the characteristics of the disease, since there is a shortage of studies that highlight them.

All authors declare no potential conflict of interest related to this article.

Work performed at Santa Casa de São Paulo, Pavilhão Fernandinho Simonsen, Pediatric Orthopedics and Traumatology Group, São Paulo, SP, Brazil. Correspondence: Ellen Goiano, Rua Dr. Cesário Mota Júnior, 112, Pavilhão Fernandinho Simonsen, 2o andar, São Paulo, SP, Brazil, 01221020. ellengoiano@hotmail.com 
The incidence of DDH for children without associated risk factors is estimated at 11.5/1,000 live births, based on meta-analysis protocols and multiple logistic regression. ${ }^{5}$ When the risk is calculated for each sex separately, the incidence ranged from 4.1/1,000 for boys to $19 / 1,000$ for girls. The relative risk with positive family history is 1.7 times higher (6.4/1,000 for boys and 32/1,000 for girls) and at pelvic presentation the relative risk compared with vertex is 6.3 times higher (29/1,000 for boys and 133/1,000 for girls).

For each male patient there are 4 or 5 female patients ${ }^{4}$, which made us infer that the epidemiology and demographic characteristics reported in the literature predominantly reflect the characteristics of $\mathrm{DDH}$ in girls.

The objective of this study was to evaluate the epidemiological characteristics of developmental dysplasia of the hip in males and secondly to investigate if these characteristics are the same as those generally reported in the literature.

\section{MATERIALS AND METHODS}

This study was based on the review of medical records of all male patients registered with the diagnosis of developmental dysplasia of the hip at the Pediatric Orthopedics Outpatient Clinic of Santa Casa de São Paulo. We found 297 male patients from a total of 2,000 consecutive cases of DDH, recorded from May 1974 to June 2009. The study design was cross-sectional.

The criteria for inclusion in the study were: having a diagnosis of developmental dysplasia of the hip in any form of presentation (instability, dysplasia, subdislocation and dislocation); being male; having been included in the DDH protocol of the reference center concerned. Patients with atypical acetabular dysplasia and/or hip dislocation or acquired otherwise (traumatic, infectious, etc.), those who had poorly completed medical records, lacking the epidemiological data necessary to conduct the work, and those who underwent some kind of previous therapeutic intervention for DDH elsewhere were excluded.

We collected data from medical records and reviewed the radiographs of each patient's medical file for epidemiological data that could show possible differences between females and males such as race, laterality, age at diagnosis, Acetabular Index (AI) at diagnosis (up to 8 years old), type of DDH according to the Tönnis Classification and according to the International Hip Dysplasia Institute (IHDI) classification (up to 4 years old).

The Al was considered altered when it was above 30 degrees in younger children and above 20 degrees in children older than 2 years of age.

To categorize the type of $\mathrm{DDH}$, the hip was classified as Instability when there were no signs of dysplasia in X-rays (XR) but there was a positive Barlow/Ortolani description on physical examination; Dysplasia when the acetabular index was increased in relation to the respective age group, but without the breaking of the Shenton Arch or lateralization of the femur (Tönnis Grade I) (Figure 1); Subdislocation with any acetabular index, associated with Shenton's arch fracture and/or femur lateralization (Tönnis Grade II), with hip centralization on the frog position radiograph (Lauenstein); Low dislocation similar to subdislocation but without hip normalization at Lauenstein position (Tönnis Grade III); and High dislocation when the femur head/proximal metaphysis cranially exceeded the Hilgenheiner line for the IHDI classification or the lateral edge of the acetabulum (Tönnis Grade IV).

For the IHDI Classification the parameter used was the location of the midpoint of the upper face of the metaphysis (H-Point) and D-line, which divides Ombredanne's inferolateral quadrant at 45 degrees, forming two hemiquadrants (Figure 2). It has been used in children from birth until 48 months of age, characterizing the most medially centered hip as Grade I and the others with progressive severity from II to IV.

After data collection the variables were statistically analyzed using the SPSS program (IBM Version 13.0 IBMä). Besides descriptive analysis, Pearson's chi-square test and Kappa agreement index were evaluated when relevant.
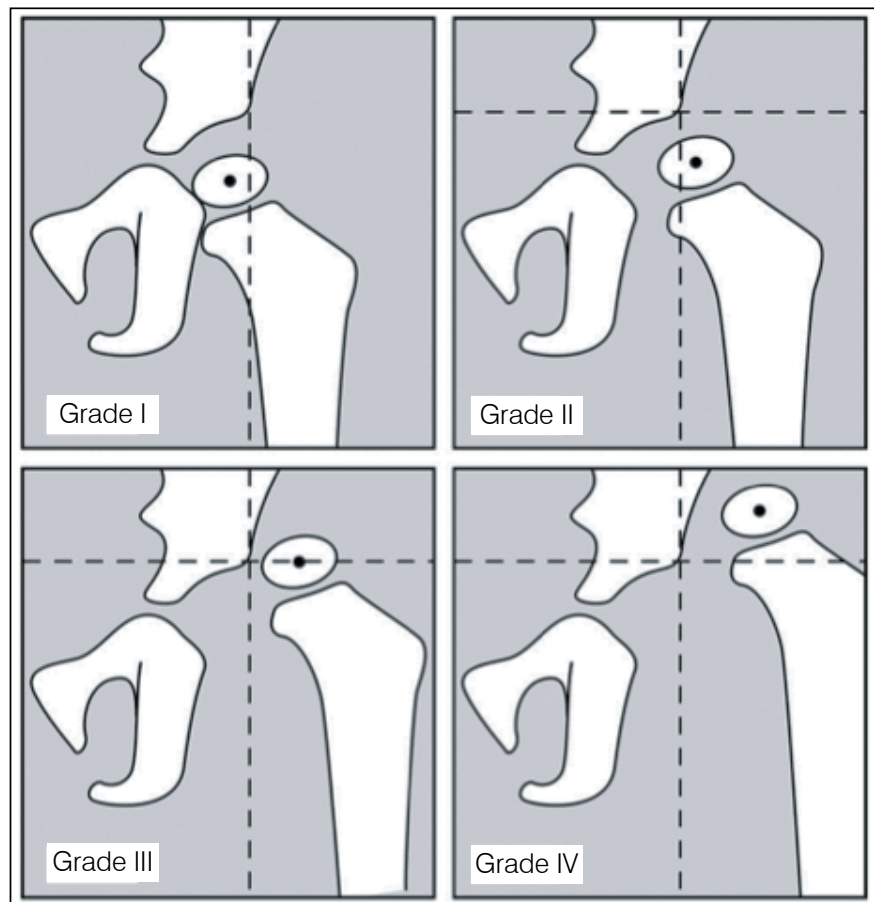

Source: Adapted from Narayanan $\mathrm{U}$ et al.

Figure 1. Tönnis classification for developmental dysplasia of the hip.

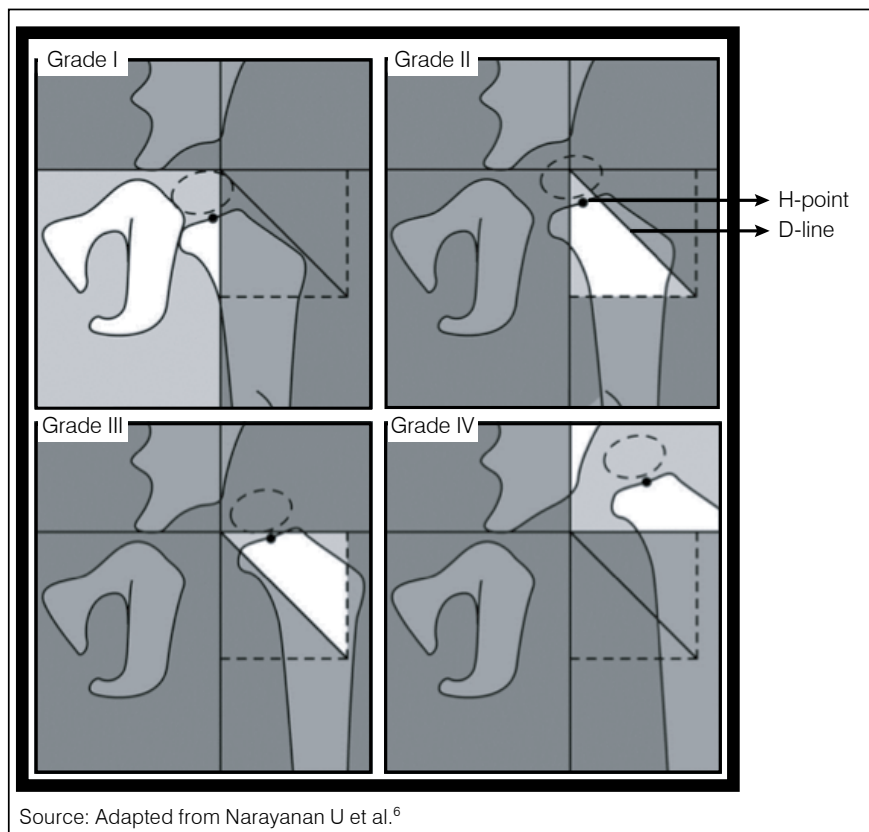

Figure 2. Classification of the International Hip Dysplasia Institute 
This study was approved by the Ethics Committee of the Faculdade de Ciências Médicas da Santa Casa de São Paulo on Nov 25, 2014. Opinion number: 895.438. CAAE: 38084214.9.0000.5479. As this was a retrospective and observational study, informed consent form was waived.

\section{RESULTS}

Of these 297 registered cases, 106 were excluded because their medical records did not include the clinical and/or radiographic information considered valid for the epidemiological analysis in question, 9 patients had no clinical and/or radiographic signs of $\mathrm{DDH}, 21$ were excluded because they were submitted to previous surgical treatment, and 14 for presenting atypical forms (syndromic or teratologic) of hip dysplasia. There were 147 patients (216 affected hips), 24 of whom had only initial radiographs and did not follow through with the service.

Age at diagnosis ranged from birth to 14 years of age (adolescent dysplasia), with a mean of 22.8 months (median 10.1 months). Almost half of the patients, 66 boys (45\%) were diagnosed before 6 months of age, 42 of them were diagnosed between 6 months and 2 years of age (28.5\%) and 39 (26.5\%) were diagnosed after 2 years (Table 1). Regarding the season of birth, 54 boys were born in autumn (36.8\%), 44 in winter (29.9\%), 25 in summer (17\%) and 24 in spring (16.3\%).

The distribution by race was 113 (76.9\%) Caucasian patients, 6 (4.1\%) brown, 4 (2.7\%) black and 24 (16.3\%) did not report. Of the 147 patients, 94 were from São Paulo capital (63.9\%), 40 (27.2\%) from the interior of the state, and only 3 came from other states. In 10 patients this information was not obtained.

Regarding laterality, 69 (46.9\%) boys had bilateral DDH, 51 (34.7\%) had dysplasia exclusively on the left side, and 27 (18.4\%) only on the right side, totaling 216 affected hips.

Regarding the type of DDH found on the initial radiograph, 62 had high dislocation (28.7\%), a similar number of 60 (27.8\%) subdislocations, followed by 44 hips with low dislocations (20.3\%), 35 hips with isolated dysplasias(16.2\%), and 15 hips with instability without dysplasia (6.9\%).

\begin{tabular}{|c|c|c|c|}
\hline Age of diagnosis & DDH Type & Laterality & Total \\
\hline $0-6$ months & $\begin{array}{c}15 \text { instabilities } \\
32 \text { dysplasias } \\
44 \text { subdislocations } \\
16 \text { low dislocations } \\
3 \text { high dislocations }\end{array}$ & $\begin{array}{c}45 \text { bilateral } \\
12 \text { left } \\
8 \text { right }\end{array}$ & $\begin{array}{l}66 \text { patients (45\%) } \\
110 \text { hips (50.9\%) }\end{array}$ \\
\hline$>6-24$ months & $\begin{array}{l}11 \text { subdislocations } \\
22 \text { low dislocations } \\
16 \text { high dislocations }\end{array}$ & $\begin{array}{c}10 \text { bilateral } \\
17 \text { left } \\
12 \text { right }\end{array}$ & $\begin{array}{c}42 \text { patients }(28.5 \%) \\
49 \text { hips }(22.7 \%)\end{array}$ \\
\hline$>24$ months & $\begin{array}{c}3 \text { dysplasias } \\
5 \text { subdislocations } \\
6 \text { low dislocations } \\
43 \text { high dislocations }\end{array}$ & $\begin{array}{l}14 \text { bilateral } \\
22 \text { left } \\
7 \text { right }\end{array}$ & $\begin{array}{c}39 \text { patients }(26.5 \%) \\
57 \text { hips }(26.4 \%)\end{array}$ \\
\hline
\end{tabular}

Also in relation to the type of $\mathrm{DDH}$, the data of respective radiographic Type, IHDI classification and acetabular index (AI) found in each patient's initial radiograph (Table 2) were crossed. The mean acetabular index on AP radiograph was 37 degrees with a standard deviation of 7.5, and on Lauenstein it was 36 degrees with a standard deviation of 7.6.
Table 2. Relationship between type of developmental dysplasia of the hip, International Hip Dysplasia Institute classification and acetabular index

\begin{tabular}{|c|c|c|c|c|}
\hline DDH Type & IHDI & Al (AP) & Al (Frog-leg) & Total \\
\hline Instability & $\begin{array}{l}14 \text { type I } \\
1 \text { type II }\end{array}$ & $\begin{array}{c}18^{\circ}-29^{\circ} \\
\text { Mean }\left(25.1^{\circ}\right)\end{array}$ & $\begin{array}{c}18^{\circ}-28^{\circ} \\
\text { Mean }\left(24.2^{\circ}\right)\end{array}$ & $\begin{array}{c}15 \text { hips } \\
7 \text { left } \\
8 \text { right }\end{array}$ \\
\hline Dysplasia & $\begin{array}{l}13 \text { type I } \\
20 \text { type II }\end{array}$ & $\begin{array}{c}30^{\circ}-46^{\circ} \\
\text { Mean }\left(34.7^{\circ}\right)\end{array}$ & $\begin{array}{c}22^{\circ}-44^{\circ} \\
\text { Mean }\left(32.9^{\circ}\right)\end{array}$ & $\begin{array}{c}33 \text { hips } \\
17 \text { left } \\
16 \text { right }\end{array}$ \\
\hline Subdislocation & $\begin{array}{l}52 \text { type II } \\
4 \text { type III }\end{array}$ & $\begin{array}{c}25^{\circ}-50^{\circ} \\
\text { Mean }\left(36.6^{\circ}\right)\end{array}$ & $\begin{array}{c}26^{\circ}-50^{\circ} \\
\text { Mean }\left(35.1^{\circ}\right)\end{array}$ & $\begin{array}{c}56 \text { hips } \\
27 \text { left } \\
29 \text { right }\end{array}$ \\
\hline Low dislocation & $\begin{array}{c}1 \text { type II } \\
43 \text { type III }\end{array}$ & $\begin{array}{c}15^{\circ}-50^{\circ} \\
\text { Mean }\left(38.8^{\circ}\right)\end{array}$ & $\begin{array}{c}24^{\circ}-50^{\circ} \\
\text { Mean }\left(38.2^{\circ}\right)\end{array}$ & $\begin{array}{c}4 \text { hips } \\
29 \text { left } \\
15 \text { right }\end{array}$ \\
\hline High dislocation & 38 type IV & $\begin{array}{c}33^{\circ}-54^{\circ} \\
\text { Mean }\left(42.2^{\circ}\right)\end{array}$ & $\begin{array}{c}32^{\circ}-58^{\circ} \\
\text { Mean }\left(41.8^{\circ}\right)\end{array}$ & $\begin{array}{l}38 \text { hips } \\
20 \text { left } \\
18 \text { right }\end{array}$ \\
\hline
\end{tabular}

IHDI: International Hip Dysplasia Institute; Al: Acetabular Index; AP: Anteroposterior incidence

\section{DISCUSSION}

The epidemiology of DDH has always been considered a conundrum due to the lack of standardization of criteria by various authors in the literature. ${ }^{1}$ There is much diversity in the studies regarding the definition of DDH itself, as already mentioned in the introduction, and on aspects such as diagnostic methods, classification, among others. ${ }^{2}$ In addition, the literature is very scarce regarding the possible sex differences concerning the epidemiology, risk factors and prognosis of evolution. In 2010, the International Committee for Medical Journal Editors (ICMJE) recommended the inclusion of representative populations in all clinical studies, including gender. Therefore, the present study was designed following the recommendation of the 2016 Sex and Gender Equity in Research (SAGER) ${ }^{7}$ guidelines in all its stages.

In this study, the 14 patients with syndromes associated with hip dysplasia were excluded, but they accounted for only $4.7 \%$ of the total sample (297 boys). Dunn (1976) described that DDH in boys usually occurs in association with other concomitant deformities and oligohydramnios, while in girls DDH is more associated with hormone-induced capsular ligament laxity. ${ }^{3} \mathrm{~A}$ limitation of our study was the impossibility of retrospectively verifying the occurrence of primiparity, pelvic delivery, oligohydramnios and a positive family history, as this information was not included in the children's medical records.

In our bibliographic research we found only two studies exclusively focused on DDH in males and only one of them addresses epidemiological aspects. ${ }^{8,9}$ In the study conducted by Samarah, Al Hadidi, Hamdan and Hantouly $(2016)^{9}$, boys with neuromuscular syndromes and diseases were excluded and not mentioned. In the other, conducted by Borges, Kumar and Guille (1995) ${ }^{8}$, the objective was to evaluate factors associated with treatment outcome, but nevertheless it was used as a reference for comparison. The said study, carried out from 1965 to 1990, identified 92 boys (143 hips) with DDH in their form of frank dislocation, with or without previous treatment. Among these, 37 (40.2\%) were associated with syndromic forms or neuromuscular diseases, much higher data than those found in our survey. We justify this difference by the fact that we are in a reference center where patients with neuromuscular diseases are directly referred for specific treatment at the Neuromuscular Diseases Clinic. 
The incidence and prevalence of DDH vary considerably across individuals of different ethnicities and geographical locations. According to the American Academy of Pediatrics ${ }^{5}$, the overall relative risk of $\mathrm{DDH}$ incidence in children is $11.5 / 1000$ live births, $4.1 / 1000$ in boys and $19 / 1000$ in girls. When there is family history or pelvic presentation this risk is even greater. We estimate that the incidence of DDH in our population is 4.6-5/1000 live births, according to the main studies conducted in South America ${ }^{10,11}$ in predominantly Caucasian individuals. Based on the data we obtained, the gender incidence ratio is 1 boy for every 5.7 girls in the 2,000 medical records evaluated.

Our series included patients cataloged for 35 years, in a total of 2,000 consecutive cases, where 297 patients were male (14.8\%) and 1,703 female (85.2\%). The incidence in girls was higher than the world average of $75.5 \%{ }^{4}$. However, for the epidemiological analysis we computed only the 147 patients (216 hips) who were referred for primary treatment and had in their medical records all the clinical/radiographic data necessary for the survey. This significant loss, in part, is probably related again to the fact that we are in a reference center to which many patients are referred only after initial treatment in other hospitals.

Regarding the period of birth, $66.7 \%$ of patients were born in "cold" months, 54 boys were born in autumn (36.8\%), 44 in winter (29.9\%), 25 in summer (17\%) and 24 in spring (16.3\%). In the study by Loder and Skopelja (2011) ${ }^{4}$, most of the included studies showed an increased incidence of DDH in children born in fall/winter months, both in the northern and southern hemispheres, corroborating the data of this research.

In this study we used the definition of race based on the work of Eveleth and Tanner (1990) ${ }^{12}$, who chose a version based on historical and geographical criteria to define populations, and although there are possible failures due to the miscegenation of the Brazilian population, the scope of the authors' survey is broad in both quantitative and qualitative terms and considered valid for other epidemiological studies. In our study there was a predominance of patients who were declared Caucasian at the initial appointment, in a total of 113 patients (76.9\%). These data are in line with general knowledge about the epidemiology of DDH. The data available in the literature for South America consider an incidence of $69 \%$ in Caucasians, irrespective of sex 4,13

Regarding laterality, 69 (46.9\%) boys had bilateral DDH, 51 (34.7\%) had dysplasia exclusively on the left side, and 27 (18.4\%) only on the right side, totaling 216 affected hips. In this regard, we found the largest variation as compared to other studies.

The systematic review by Loder and Skopelja (2011) ${ }^{4}$ based on English-language articles published between 1947 and 2010 focused exclusively on etiological, epidemiological and diagnostic aspects and provided good scientific support for comparison with the data found here. From a total of 9,717 cases studied, $63.4 \%$ presented unilateral involvement, of which $36 \%$ involved the right side and $64 \%$ the left side, leaving $36.6 \%$ of bilaterality. Although the left side is typically more involved, significant ethnic variation was found, being smaller in the Indo-Mediterranean (44\%) and larger in the Australians/New Zealanders (81.4\%). South Americans had a balanced distribution with $52 \%$ on the left side and $48 \%$ on the right side.

In our study, left dysplasia had a much higher incidence in unilateral cases. When we consider only these patients (78 boys), the statistics are similar to the data reported by Borges et al. (1995) ${ }^{8}$ with $65.4 \%$ of DDH exclusively on the left (Borges $-62.5 \%$ ) and $34.6 \%$ on the right (Borges $-37.5 \%$ ), both including only the male pediatric population.

In this study, the high incidence of bilaterality was considered an impacting factor of difference from the current literature, which describes little variation of $\mathrm{DDH}$ by sex in the different races, but considerable variation in bilaterality. ${ }^{4}$ In our series, besides the predominance of Caucasian patients, the incidence of bilaterality (46.9\%), although lower than the $60.5 \%$ found by Samarah et al. $(2016)^{9}$, was similar to that found by Borges $(41.8 \%)^{8}$. Caucasian South Americans were considered ethnically the patients with the highest incidence of bilateral DDH (69\%). This statement was based on the study byRomero et al. (1989) ${ }^{13}$, who analyzed 97 Chilean patients, regardless of sex, where only 13 (13.4\%) were boys. If we consider that the studies by Samarah and Borges were carried out exclusively with male patients and analyzing the four studies in question, including the present one, in all of them the incidence of bilaterality in the male population was higher than reported in the literature, and this reinforces that there are epidemiological gender differences to be considered.

The mean age at diagnosis of our patients was 22.8 months (median 10.1 months) with 66 boys (45\%), i.e. about half of them diagnosed before 6 months of age, and 39 patients (26.5\%) had a "late" diagnosis after 2 years old. A Canadian study ${ }^{14}$ considering 20 months of age as the cutoff point found that the main factor associated with late diagnosis was bilateral presentation (44\%), similar to this study. In the study by Samarah et al. $(2016)^{9}$, who investigated 1,145 boys and found 43 children with DDH (70 hips), the main factors associated with late presentation in males were primiparity and bilaterality.

At the time of diagnosis, the patients were radiographically classified according to DDH type, and we observed that upper hip dislocation along with subdislocations were the most prevalent presentations, with 62 hips affected by the former (28.7\%) and 60 hips by the latter, respectively (27.8\%). Together they represented $56.5 \%$ of the cases, while patients with isolated instabilities and dysplasia were the least representative of the sample with $13.1 \%$. Despite being found in all age groups of our study, high dislocation showed a significant increase in the older the patient, unlike the subdislocations, which were more frequent in the youngest age group (0-6 months). This progression of DDH makes us infer a worse prognosis the older the age, which is not exclusive to males, but draws attention to an earlier diagnosis.

In the radiographic evaluation, the progression of the Acetabular Index on AP radiograph was assessed according to the severity of the type found. In cases of pure instability the mean was 25.1 degrees, and in cases of high dislocation 42.2 degrees. This gradual increase in angles is in line with the concept of developmental dysplasia as a progressive disorder of the hip, considering the finding that the vast majority of cases of high dislocation were diagnosed in older patients. As compared to other articles on the subject, the mean and standard deviation of Al on AP radiograph were similar to those found in the literature. We did not find references to acetabular index values in Lauenstein pelvic radiograph (frog-leg position), all reference authors in their classic studies for acetabular index did so on the anteroposterior radiograph $(\mathrm{AP})^{15-19}$.

Many studies have been written discussing the so-called normal values for the acetabular index. Kleinberg and Lieberman (1936) ${ }^{15}$ found a mean index of 27.5 degrees in newborns and 20 degrees in 11-24-month-olds, while in 12-36-month-olds with dysplastic hip the mean index was 37.5 degrees. Despite the controversies regarding this study, especially regarding the proper positioning of the patient and the possible variations in the angle $\mathrm{e}^{17,18}$, it remains a good reference for diagnosis and evolution of the cases provided it is used in conjunction with the well-established clinical parameters ${ }^{19}$. Broughton, Brougham, Cole and Menelaus (1989) ${ }^{16}$ investigated the intra- and interobserver correlation of several possible assessments for acetabular dysplasia and found great variability between measurements. Of all the parameters studied, the acetabular index 
was the most accurate, with 95\% agreement between observers. In our study, the relative values of the acetabular index in Lauenstein incidence were always slightly lower than values of the same angle in the AP radiograph, but with a very similar mean. It is possible that the frog incidence is more accurate than AP radiograph when the exams come from non-standard radiology services, because in this position the flexion and abduction of the hips, in addition to decreasing lumbar lordosis correcting the pelvis, make the child be positioned more in front of the equipment, decreasing the lateral inclination and, consequently, the angle variation.

When we crossed the data of the acetabular index with the type of DDH and the $\mathrm{IHDI}$ classification, we found a close correlation between radiographic type and classification and, although not a specific objective of this research, it evidenced and validated for us the reproducibility of the classification proposed by the International Hip Dysplasia Institute as an "evolution" of the classic Tönnis Classification, because the IHDI classification is independent of the appearance of the proximal secondary ossification center of the femur to be applied ${ }^{6.20}$
Therefore, we consider from the above-mentioned factors that the higher incidence of bilaterality in males is a factor that may justify late diagnosis and, consequently, the higher incidence of high dislocations with a tendency to a worse prognosis.

These findings emphasize the need for both a more vigilant assessment in the neonatal diagnosis and the institution of treatment as soon as the condition is identified, as well as mandatory screening tests in all maternity wards and for all newborns, regardless of the presence or absence of risk factors.

\section{CONCLUSIONS}

$\mathrm{DDH}$ in males presents different characteristics from those reported in the literature. We found a higher frequency of bilaterality, later age of diagnosis and a higher percentage of high dislocations than in other epidemiological studies. Therefore we recommend the diagnostic investigation in the maternity ward for both sexes, regardless of the presence of risk factors.

AUTHORS' CONTRIBUTIONS: Each author contributed individually and significantly to the development of this article. EOG: radiographic analysis, database construction, article writing, statistical analysis and intellectual concept of the article and preparation of the entire research project; MA: critical review of the intellectual content of the paper and review of the article; JPP: radiographic analysis and database construction; CS: writing and proofreading of the article as well as the entire intellectual concept of the article.

\section{REFERENCES}

1. MacFarlane A. Congenital dislocation of the hip: an epidemiological conunmdrum Matern Child Health J. 1980;13-15.

2. Musielak B, Idzior M, Jóźwiak M. Evolution of the term and definition of dysplasia of the hip: a review of the literature. Arch Med Sci. 2015;11(5):1052-7.

3. Dunn PM. Perinatal observations on the etiology of congenital dislocation of the hip. Clin Orthop Relat Res. 1976;119:11-22

4. Loder RT, Skopelja EN. The epidemiology and demographics of hip dysplasia. ISRN Orthop. 2011;2011:238607

5. Committee on Quality Improvement. Clinical practice guideline: early detection of developmental dysplasia of the hip. Pediatrics. 2000;105(4 Pt 1):896-905.

6. Narayanan U, Mulpuri K, Sankar WN, Clarke NM, Hosalkar H, Price CT, et al Reliability of a new radiographic classification for developmental dysplasia of the hip. J Pediatr Orthop. 2015;35(5):478-84.

7. Heidari S, Babor TF, Castro P, Tort S, Curno M. Sex and gender equity in research: rationale for the SAGER guidelines and recommended use. Epidemiol Serv Saude. 2017;26(3):665-75.

8. Borges JLP, Kumar SJ, Guille JT. Congenital dislocation of the hip in boys. J Bone Joint Surg Am. 1995;77(7):975-84.

9. Samarah $O Q$, Al Hadidi FA, Hamdan MQ, Hantouly AT. Late-presenting developmental dysplasia of the hip in Jordanian males: a retrospective hospital based study. Saudi Med J. 2016;37(2):151-5.

10. Tijmes J, Garrido LQ, Pasik SF, Quintana B. Displasia de cadera: pesquisa en la provincia de Llanquihue. Rev Chil Pediatr. 1971;42:633-9.

11. Guarniero R, Montenegro NB, Vieira PB, Peixinho M. Sinal de Ortolani: resultado do exame ortopédico em 9171 recém-nascidos na Associação Maternidade de São Paulo. Rev Bras Ortop 1988;23(5):125-8.

12. Eveleth PB, Tanner JM. Worldwide Variation in Human Growth. 2nd ed. Cambridge: Cambridge University Press; 1990

13. Romero MI, Julián M, Gaete V, Bedregal P, Pinto JI, Castiglione C. Epidemiologic characteristics of congenital hip dysplasia in a Chilean population. Rev Chi Pediatr. 1989;60(5):268-71.

14. Haasbeek JF, Wright JG, Hedden DM. Is there a difference between the epidemiologic characteristics of hip dislocation diagnosed early and late? Can J Surg 1995;38(5):437-8.

15. Kleinberg S, Lieberman HS. The acetabular index in infants in relation to congenital dislocation of the hip. Arch Surg. 1936;32(6):1049-54.

16. Broughton NS, Brougham DI, Cole WG, Menelaus MB. Reliability of radiological measurements in the assessment of the child's hip. J Bone Joint Surg Br. 1989;71(1):6-8

17. Laurenson D. The acetabular index: A critical review. J Bone Joint Surg Br 1959;41B(4):702-10

18. Schwartz DR. Acetabular development after reduction of congenital dislocation of the hip: a follow-up study of fifty hips. J Bone Joint Surg Am. 1965;47:705-14.

19. Mladenov K, Dora C, Wicart P, Seringe R. Natural history of hips with borderline acetabular index and acetabular dysplasia in infants. J Pediatr Orthop. 2002;22(5):607-12.

20. Miao M, Cai H, Hu L, Wang Z. Retrospective observational study comparing the international hip dysplasia institute classification with the Tönnis classification of developmental dysplasia of the hip. Medicine (Baltimore). 2017;96(3):e5902. 